\title{
Special Feature: Multidisciplinary Social Networks Topics and Research Trends
}

\author{
I-Hsien Ting ${ }^{1}$
}

Published online: 23 April 2019

๑ Springer Japan KK, part of Springer Nature 2019

The title of the special feature is "Multidisciplinary Social Networks Topics and Research Trends" and includes papers that cover different aspect of social networks research. In this special issue, we invited authors to submit extended version of their papers, which are selected top quality papers from MISNC 2018 (The 5th Multidisciplinary International Social Networks Conference, St-Etienne, France). In addition to the invited papers, we also called for public submissions.

The first paper in the special issue is entitled "Learning styles in a collaborative algorithmic problem-based learning", which is co-authored by Teimzit Amira, Mahnane Lamia and Hafidi Mohamed. In the paper, the authors proposed problembased learning by applying Felder-Silverman's model of learning styles and intelligent technologies, such as ontology and data mining methods. The focus of the cases are algorithmic courses taught in the first year of computer science program.

The second paper is authored by Hioroshi Koga and entitled "An Essay on the Taxonomy and Trajectory of Social Media Marketing From customer information to customer experience". In this paper, the author aims to propose "standard" tactics about changes in the focus of marketing approaches using social media. The author uses two types of context and marketing methods as uncontrollable media and finally proposed a trajectory of social media marketing.

The third paper is entitled "Realizing Social-Media-Based Analytics for Smart Agriculture" and the authors of the paper are M. Saravanan and Satheesh K. Perepu. In this paper, the authors proposed a new framework for identifying the relevant details of plants from text and images. The approach is very useful to generate knwoledge about plant diseases and precision agriculture. The proposed model is also evaluated and implemented on social media.

The fourth paper is co-authored by Georgios Lappas, Amalia Triantafillidou and Prodromos Yannas, which is entitled "Members of European Parliament (MEPs) on Social Media: Understanding the Underlying Mechanisms of Social Media Adoption and Popularity". In the paper, it examines the usage of social media by members

I-Hsien Ting

iting@nuk.edu.tw

1 National University of Kaohsiung, Kaohsiung, Taiwan 
of the European Parliament as well as the differences in social media usage between two different MEPs period. It also tests the impact of several predictors on MEPs social media adoption and popularity. The results of the study suggest that social media popularity of MEPs can be predicted and also shows how the two platforms differ in regard to the factors.

The fifth paper is the last paper in the special issue which is entitled "The Roles of ICTs in Product Innovation in Southeast Asia". The authors of the paper are Yesushi Ueki and Masatsugu Tsuji. In this paper, the authors intend to examine the relationship between ICT us and product innovation among firms in Lao PDR, Thailand and Vietnam. It also examines the cause-effect relationship among different use of ICT. SEM is used to analyse the questionnaire survey data. The paper is concluded with an interesting finding that firms with higher capacity for sharing and developing information inside the firm can promote ICT use for obtaining external information which shows the opposite of results gained from the authors' previous research.

Publisher's Note Springer Nature remains neutral with regard to jurisdictional claims in published maps and institutional affiliations. 